\title{
Nutrient Selection in the Absence of Taste Receptor Signaling
}

\author{
Xueying Ren, ${ }^{1,2}$ Jozélia G. Ferreira, ${ }^{1,2}$ Ligang Zhou, ${ }^{3}$ Sara J. Shammah-Lagnado, ${ }^{5}$ Catherine W. Yeckel, ${ }^{1,4}$ \\ and Ivan E. de Araujo ${ }^{1,2}$ \\ ${ }^{1}$ The John B. Pierce Laboratory, New Haven, Connecticut 06519, Departments of ${ }^{2}$ Psychiatry, ${ }^{3}$ Internal Medicine, and ${ }^{4}$ Epidemiology and Public Health, \\ Yale University School of Medicine, New Haven, Connecticut 06520, and ${ }^{5}$ Department of Physiology and Biophysics, Institute of Biomedical Sciences, \\ University of São Paulo, CEP 05508-900, São Paulo, São Paulo, Brazil
}

When allowed to choose between different macronutrients, most animals display a strong attraction toward carbohydrates compared with proteins. It remains uncertain, however, whether this food selection pattern depends primarily on the sensory properties intrinsic to each nutrient or, alternatively, metabolic signals can act independently of the hedonic value of sweetness to stimulate elevated sugar intake. Here we show that $\operatorname{Trpm} 5^{-/-}$mice, which lack the cellular mechanisms required for sweet and several forms of $\mathrm{L}$-amino acid taste transduction, develop a robust preference for $\mathrm{D}$-glucose compared with isocaloric L-serine independently of the perception of sweetness. Moreover, a close relationship was found between glucose oxidation and taste-independent nutrient intake levels, with animals increasing intake as a function of glucose oxidation rates. Furthermore, microdialysis measurements revealed nutrient-specific dopaminergic responses in accumbens and dorsal striatum during intragastric infusions of glucose or serine. Specifically, intragastric infusions of glucose induced significantly higher levels of dopamine release compared with isocaloric serine in both ventral and dorsal striatum. Intragastric stimulation of dopamine release seemed to depend on glucose utilization, because administration of an anti-metabolic glucose analog resulted in lower dopamine levels in striatum, an effect that was reversed by intravenous glucose infusions. Together, our findings suggest that carbohydrate-specific preferences can develop independently of taste quality or caloric load, an effect associated with the ability of a given nutrient to regulate glucose metabolism and stimulate brain dopamine centers.

\section{Introduction}

To maintain normal physiological functions, animals must obtain metabolic fuels from a diverse array of macronutrients. Animals rely primarily on chemoreceptor systems, such as gustation, to establish consummatory preferences among available food sources. In fact, taste quality seems to act as the one main factor accounting for the generally increased preferences toward carbohydrates compared with amino acids and proteins. More specifically in mice, it has been shown with gustatory tests that the behavioral potency of sucrose is far superior to those of glycine or L-serine (Dotson and Spector, 2004). Forty-eight-hour twobottle tests revealed in addition that mice consume significantly higher levels of glucose compared with the sweet-tasting amino acid L-serine (Bachmanov and Beauchamp, 2008). Accordingly, it has been suggested that the behavioral attraction associated with a given nutrient reflects its intrinsic ability to bind the sweet T1R2/T1R3 receptor on the tongue (Dotson and Spector, 2004).

It must also be noticed, however, that carbohydrates and amino acids will typically stimulate distinct metabolic pathways. Particularly important is the fact that dietary amino acids and

Received Nov. 19, 2009; revised March 30, 2010; accepted April 7, 2010.

J.G.F. was the recipient of a Coordenação de Aperfeiçoamento de Pessoal de Nível Superior Brazil PhD scholarship

Correspondence should be addressed to Ivan E. de Araujo, The John B. Pierce Laboratory and Yale University

School of Medicine, 290 Congress Avenue, New Haven, CT 06519. E-mail: IAraujo@jbpierce.org.

D01:10.1523/JNEUROSCI.5749-09.2010

Copyright $\odot 2010$ the authors $\quad 0270-6474 / 10 / 308012-12 \$ 15.00 / 0$ sugars differentially control the relative amounts of insulin and glucagon to be secreted by the pancreas (Young, 2005; Ji and Bachmanov, 2007), an effect that will directly influence the organism's ability to mobilize stored fuels (Ferrer et al., 2003; Buch et al., 2008). This suggests that appetites for these macronutrients might be under the control of metabolic needs in addition to taste quality, as evidenced by increased intake levels of essential amino acids that had been withdrawn from an animal's diet (Markison et al., 1999).

Therefore, it is possible that postingestive effects, acting independently of taste quality, function as physiological reinforcers, ultimately leading to increased sugar intake (Sclafani, 2001; Glendinning et al., 2007). Here we tested the hypothesis that D-glucose will be consumed at higher levels compared with a free L-amino acid even when gustatory influence is eliminated and that such an effect is associated with nutrient-specific responses in brain dopamine systems. To address this issue, we performed our behavioral experiments in mice lacking a functional transient receptor potential channel M5 (Zhang et al., 2003) [knock-out (KO) Trpm $5^{-1-}$ mice]. The TRPM5 ion channel is expressed in taste receptor cells (Pérez et al., 2002; Roper, 2007) and is required for bitter, sweet, and most forms of L-amino acid taste signaling (Zhang et al., 2003). We reasoned that, if postingestive factors influence the augmented intake levels associated with sugars, then the sweet-indifferent and L-amino-acid-indifferent $\mathrm{KO}$ animals would develop a preference for food dispensers associated with the availability of glucose compared with those associ- 
ated with L-amino acid solutions. Moreover, using metabolic measurements, we tested the hypothesis that taste-independent sugar preferences are associated with the ability of the body to use glucose as a fuel. Finally, we investigated whether administering glucose and L-amino acids directly into the gut induces nutrientspecific dopaminergic responses in the striatum. In fact, extracellular dopamine levels in this region are associated with both the hedonic (Hajnal et al., 2004) and the postingestive (de Araujo et al., 2008) effects of sugar intake. More generally, dopamine signaling in the striatum is implicated in the regulation of food reinforcement (Hernandez and Hoebel, 1988; Grigson and Hajnal, 2007). Accordingly, we hypothesized that nutrientspecific activations of brain dopamine centers, initiated during direct stimulation of the gastrointestinal tract, reflect the onset of nutrient selection behaviors that take place independently of gustatory input.

\section{Materials and Methods}

Subjects. A total of 110 male mice with a C57BL/6 background were used. At the time of experiments, animals were 8 to 16 weeks old. Forty-two of these animals were homozygous for a partial deletion of the Trpm5 gene (KO) (Zhang et al., 2003) in which a PGK-neo cassette specifically replaced exons 15-19 encoding the first five transmembrane domains of TRPM5, rendering the channel inactive. These animals were bred at the John B. Pierce animal facilities from mice generously donated by C. S. Zuker (University of California, San Diego, San Diego, CA). Sixty-two age- and weight-matched male mice were wild-type C57BL/6 (WT) animals obtained from either the The Jackson Laboratory or the Charles Rivers Laboratory. Genotype was confirmed by PCR amplification, followed by gel electrophoresis. Trpm5-specific primers (forward, 5'-ATTCTAGAGCCCACCCGCCCCATC-3'; reverse, $5^{\prime}$-TTCACCTGCCCAGCCCTCATCTAC-3') were used to amplify a segment $>2 \mathrm{~kb}$ in WT animals and $<2 \mathrm{~kb}$ in $\mathrm{KO}$ animals. All experiments were conducted in accordance with the John B. Pierce Laboratory and Yale University regulations on usage of animals in research.

Knock-out animals were originally generated on a C57BL/6;129 background and were backcrossed with C57BL/6 wild-type animals for at least three generations. Regarding genetic background homogeneity, we stress that the primary aim of the present study was to assess changes in feeding responses in sweet- and amino-acid-insensitive Trpm 5 knockout mice. Because no specific assignment of function is being associated with the Trpm5 gene itself, the comparisons with WT animals are being performed and assessed at the strain level; therefore, our conclusions do not depend on whether or not additional components of the 129 strain genome have influenced the results. The crucial point here is that the strain associated with the deletion of the Trpm 5 gene is insensitive to the taste of sugars and amino acids but is able to develop preferences for glucose solutions based on their metabolic effects.

Stimuli and behavioral apparatus. All stimuli [D-glucose (glucose), L-serine (serine), L-arginine (arginine), and 2-deoxy-D-glucose (2-DG)] were obtained from Sigma and prepared daily in distilled water at room temperature. Behavioral experiments were conducted in either one of two identical mouse behavior chambers enclosed in a ventilated and sound-attenuating cubicle (Med Associates). Each chamber is equipped with two slots for sipper tubing placements, at symmetrical locations on one of the cage walls. All sippers are connected to a contact-based licking detection device allowing for measurements of licking responses with 10 ms resolution. All lick timestamps were saved in a computer file for posterior analysis.

Short-term two-bottle preference tests. Short-term (10 min) two-bottle preference tests between carbohydrate and amino acid solutions were used to determine the ability of KO and WT mice to display orosensorydriven preferences for one of the macronutrients. The short duration of the test aims to minimize postingestive influences. Once habituated to the behavioral chamber, each animal was presented with the choice between a carbohydrate and an amino acid solution prepared at as isoca- loric load. The number of licks in each sipper was recorded and used to calculate the preference ratio as follows:

$$
\text { Sipper1 }=\frac{n(\text { Sipper } 1)}{n(\text { Sipper } 1)+n(\text { Sipper2 })},
$$

where $n$ (Sipper $x$ ) denotes the detected number of licks to sipper $x$ during a given session. To eliminate the influence of side biases, mice were tested for 4 consecutive days with sipper positions being switched daily.

Conditioning protocol. To verify whether KO mice can develop nutrient-specific preferences, a conditioning protocol was used to allow mice to associate a sipper position with nutrient-specific postingestive effects. Conditioning experiments were conducted in naive animals after $15 \mathrm{~h}$ food/water deprivation. Side biases were determined during a 10min two-bottle water versus water tests. Then animals were conditioned for 6 (or alternatively 8) days with daily $30 \mathrm{~min}$ sessions of ad libitum access to either serine or glucose in one-bottle forced-choice training sessions. Serine was presented on a predetermined side of the chamber for $3 \mathrm{~d}$ intercalated with 3 other days, during which glucose was presented on the opposite side of the chamber. Assignments of a solution to a particular side of the chamber were chosen in a way to factor out the side biases. After training, side preferences were tested in 10-min two-bottle water versus water tests.

Indirect calorimetry. Energy expenditure was measured via indirect calorimetry using the Oxymax/CLAMS Animal Monitoring System (Columbus Instruments). This is a mouse-dedicated, four-cage system equipped with open-circuit calorimetry, contact lickometers, and $x-z$ axis motor activity sensors. Metabolism-induced heat was derived by assessing the exchange of oxygen for carbon dioxide that occurs during metabolic processes (Jéquier et al., 1987), as measured by the mass flow principle. Oxygen $\left(\mathrm{O}_{2}\right)$ measurement was performed via paramagnetic sensing and carbon dioxide $\left(\mathrm{CO}_{2}\right)$ by single-beam nondispersed infrared. The respective volumes were determined as follows:

$$
\begin{gathered}
V \mathrm{O}_{2}=V_{\mathrm{i}} \mathrm{O}_{2 \mathrm{i}}-V_{\mathrm{o}} \mathrm{O}_{2 \mathrm{o}}, \\
V \mathrm{CO}_{2}=V_{\mathrm{o}} \mathrm{CO}_{2 \mathrm{o}}-V_{\mathrm{i}} \mathrm{CO}_{2 \mathrm{i}},
\end{gathered}
$$

where $V_{\mathrm{i}}$ is mass of air at chamber input per unit time, $V_{\mathrm{o}}$ is mass of air at chamber output per unit time, $\mathrm{O}_{2 \mathrm{i}}$ is oxygen fraction in $V_{\mathrm{i}}, \mathrm{CO}_{2 \mathrm{i}}$ is carbon dioxide fraction in $V_{\mathrm{i}}, \mathrm{O}_{2 \mathrm{o}}$ is oxygen fraction in $\mathrm{V}_{\mathrm{o}}$, and $\mathrm{CO}_{2 \mathrm{o}}$ is carbon dioxide fraction in $V_{\mathrm{o}}$.

The respiratory quotient RQ was calculated as follows:

$$
R Q=V \mathrm{CO}_{2} / \mathrm{VO}_{2} \text {. }
$$

Heat was calculated by determining the calorific value of the food being metabolized. For the accepted range of nutritional RQs $(0.707-$ $1.0)$, the heat available is $4.686-5.047 \mathrm{kcal} / \mathrm{L}\left(\mathrm{O}_{2}\right)$. The calorific value $\left(\mathrm{C}_{\mathrm{v}}\right)$ is interpolated by straight line approximation for values within the $R Q$ range $\left(C_{v}=3.815+1.232 \times R Q\right)$. The resulting calorific value is applied to the obtained figure for oxygen consumption for derivation of heat, followed by normalization of this quantity to the animal's body volume:

$$
\text { Heat }=\left(\mathrm{C}_{\mathrm{v}} \times V \mathrm{O}_{2}\right) /(\text { body weight })^{0.75} .
$$

Ambulatory activity was obtained from the total number of beambreak counts of the $x-z$ sensors.

Glucose and glycogen measurements. After 1-h-long ad libitum onebottle behavioral sessions, animals were killed with an overdose of Euthasol $(0.1 \mathrm{ml})$. Liver glycogen was immediately hydrolyzed from $100 \mathrm{mg}$ of tissue using $2 \mathrm{~N} \mathrm{HCl}(0.6 \mathrm{ml})$ for $2 \mathrm{~h}$ at $\sim 100^{\circ} \mathrm{C}$. Measurement of the resulting glucose units was performed on an YSI Automated Glucose Analyzer by glucose oxidase (Yellow Springs Instruments). Data are presented as glucosyl units in micromoles per grams wet weight. Blood glucose was measured with a handheld glucometer (OneTouch), and data are presented as milligrams per deciliters. The corresponding total number of licks from each session was then entered in correlation analyses using the corr function in Matlab (R14; MathWorks). corr computes $p$ values for Pearson's coefficients $r$ using a Student's $t$ distribution for a 
transformation of the correlation. $p$ values were Bonferroni's corrected for multiple comparisons. To ascertain that the significant correlations observed were not contributed by single extreme values, nonparametric Spearman's rank correlations were computed, and significant (at least $p<0.01)$ correlations were verified in each relevant case.

Dopamine measurements during intragastric and intravenous infusions of nutrients and glucose metabolism inhibitors. Mice were placed on a stereotaxic apparatus (David Kopf Instruments) under constant flow of $\sim 1 \%$ isoflurane anesthesia $(1.5 \mathrm{~L} / \mathrm{min})$, and a circular craniotomy was drilled at either $1.2 \mathrm{~mm}$ anteroposteriorly (AP), $\pm 0.6 \mathrm{~mm}$ mediolaterally (ML) or $+1.3 \mathrm{~mm} \mathrm{AP}, \pm 1.3 \mathrm{~mm} \mathrm{ML}$ for ventral/dorsal striatum, respectively, implantation of guide cannulae $[-2.2 /-0.5 \mathrm{~mm}$ dorsoventrally (DV) from the brain surface for ventral/dorsal striatum, for posterior insertion of a microdialysis probe (final probe tip positions $[-4.2 /-2.5$ $\mathrm{mm} \mathrm{DV}]$ ). Microdialysate samples from freely moving mice were collected, separated, and quantified by HPLC coupled to electrochemical detection methods. Briefly, after recovery from surgery, a microdialysis probe [model A-I-4-02, $2 \mathrm{~mm}$ membrane length, $0.22 \mu \mathrm{m}$ outer diameter, $50 \mathrm{kDa}$ cutoff (Eicom); or $2 \mathrm{~mm}$ CMA-11, $6 \mathrm{kDa}$ cutoff (CMA Microdialysis)] was inserted into the striatum through the guide cannula [CXG-X, $500 \mu \mathrm{m}$ outer diameter (Eicom); or the corresponding CMA-11 model]. After insertion, probes were connected to a syringe pump and perfused at $0.5-2.0 \mu \mathrm{l} / \mathrm{min}$ with artificial CSF (Harvard Apparatus). After a $60 \mathrm{~min}$ washout period, dialysate samples were collected every $30 \mathrm{~min}$ and immediately manually injected into an HTEC-500 HPLC unit (Eicom). Analytes were then separated via an affinity column (PP-ODS; Eicom), and compounds were subjected to redox reactions within an electrochemical detection unit (amperometric direct current mode, applied potential range from 0 to $\sim 2000 \mathrm{mV}, 1 \mathrm{mV}$ steps). Resulting chromatograms were analyzed using the software EPC-300 (Eicom), and actual sample concentrations were computed based on peak areas obtained from $1 \mathrm{pg} / \mu \mathrm{l}$ dopamine standards (Sigma) and expressed as percentage changes with respect to the mean dopamine concentration associated with baseline (i.e., preinfusion) samples. During intragastric infusions, baseline samples (no infusions) were collected for 30/90 min, followed by activation of the infusion pump at a rate of $10 \mu \mathrm{l} / \mathrm{min}$. Three subsequent 30-min-long samples were collected and analyzed as described above. Order of nutrient infusion was assigned to each animal from a random distribution. For the case of intravenous (jugular) infusions of 2-DG and glucose, $10 \mathrm{mg}$ of 2-DG was prepared in $60 \mu \mathrm{l}$ of vehicle, and jugular infusions lasted for $6 \mathrm{~min}$ at a rate of $10 \mu \mathrm{l} / \mathrm{min}$. Four samples were collected (15 min collection time per sample). Then, a jugular infusion of $14.5 \%$ glucose started and lasted for 10 $\mathrm{min}$ at $10 \mu \mathrm{l} / \mathrm{min}$, after which two samples were collected (total of $30 \mathrm{~min}$ ). For increased time resolution, samples were collected every $15 \mathrm{~min}$ for detection of the rapid actions of 2-DG on glucose metabolism. In all cases, locations of microdialysis probes were confirmed histologically (supplemental Fig. S3, available at www.jneurosci.org as supplemental material).

\section{Results}

Trpm5 KO mice are indifferent to the choice between glucose and $\mathrm{L}$-amino acids during short-term taste tests

We started by confirming that $\mathrm{KO}$ animals are indifferent to the choice between the flavors of glucose and either one of two different L-amino acids (serine and arginine). $\mathrm{KO}$ animals $(n=5)$ and WT controls ( $n=5$, matched for age, weight, and sex) were exposed to short-term (10 $\mathrm{min}$ ) two-bottle glucose versus amino acid preference tests. The rationale for the short duration of this test is the attempt to minimize the influence of postingestive factors on consummatory behaviors. Same weight of glucose or L-amino acids (14.5 g) were dissolved in $100 \mathrm{ml}$ of distilled water, resulting in the solutions having approximately the same caloric content as a result of their similar Atwater coefficients (4 kcal/g) (Atwater, 1910; Merrill and Watt, 1973). In line with previous findings (Dotson and Spector, 2004; Bachmanov and Beauchamp, 2008), whereas WT mice strongly
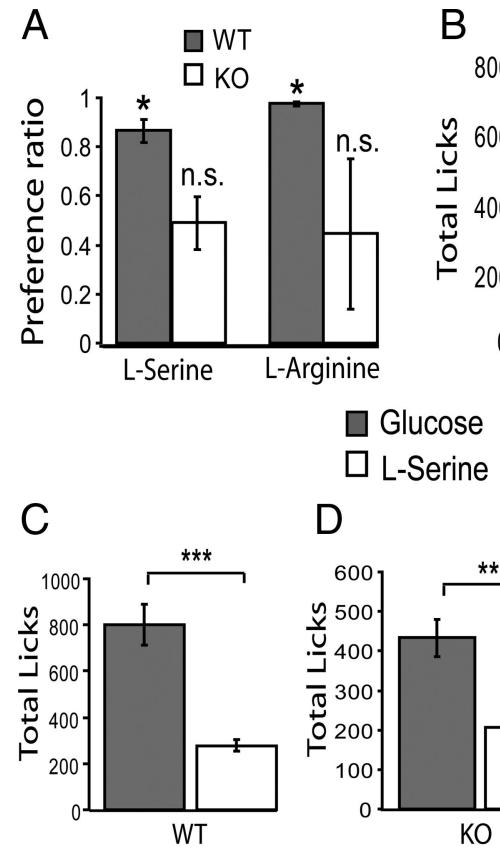

\section{$\square$ Glucose \\ $\square$ L-Serine}

D

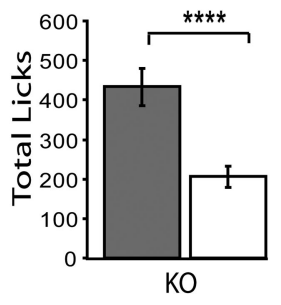

$E$

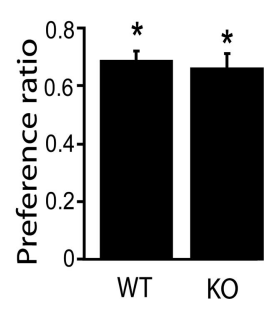

Figure 1. Trpm5 KO mice can develop a preference for glucose solutions through a conditioning protocol. Experimental data are presented as mean \pm SEM across animals throughout Results. $\boldsymbol{A}$, In short-term (10 min) two-bottle preference tests, whereas WT animals displayed strong attraction to $14.5 \%$ glucose against L-amino acids serine and arginine, with preference ratios significantly higher than $0.5, \mathrm{KO}$ animals were indifferent between the two choices $\left({ }^{*} p<\right.$ 0.001 , independent $t$ test against 0.5 ). $\boldsymbol{B}$, These findings are further confirmed by analyzing the mean total consumption data for these short-term two-bottle sessions: whereas WT animals consumed significantly more glucose than serine $\left({ }^{* *} p<0.0005\right.$, paired two-sample $t$ test $)$ and arginine (data not shown), KO mice consumed approximately the same amounts from both solutions (not significant, $p>0.4$ ). C, During 30-min-long conditioning sessions, animals were given alternated access to either glucose only (arbitrarily assigned to one sipper in the behavioral cage) or isocaloric serine only (assigned to the opposite sipper) for 6 consecutive days. During these conditioning sessions, which were designed to allow KO animals to associate a sipper side with its postingestive effects, both WT (C) and KO $(\boldsymbol{D})$ animals consumed significantly more glucose than serine (paired two-sample $t$ test, ${ }^{* * *} p<0.000006$; ${ }^{* * *} p<0.002$ ). $\boldsymbol{E}$, During 10-min-long two-bottle postconditioning test sessions in which water was accessible from both sippers, a significant higher preference toward the sipper previously associated with glucose availability were observed for both WT and $\mathrm{K} 0$ animals ( ${ }^{*} p<0.02$, independent $t$ test against 0.5 ).

preferred the taste of glucose to serine (preference ratio of $0.86 \pm 0.06 ; p<0.001$, one-sample $t$ test against the indifference ratio of $0.5 ; t=5.25)$, $\mathrm{KO}$ mice displayed a clear indifference toward the solutions $(0.57 \pm 0.12 ; p>0.55 ; t=0.61)$ (Fig. $1 A$ ). The same preference pattern was observed for the non-sweet amino acid arginine: whereas WT mice strongly preferred glucose to arginine $\left(0.96 \pm 0.01 ; p<3 \times 10^{-10} ; t=\right.$ $37.8)$, KO mice were once again indifferent to the choice $(0.44 \pm 0.30 ; p>0.8 ; t=-0.2)$.

The indifference displayed by Trpm $5 \mathrm{KO}$ mice during the short-duration two-bottle tests becomes even clearer when the mean total consumption data are analyzed (Fig. $1 B$ ). Whereas WT mice consumed significantly larger amounts of the glucose solution compared with serine $(604.7 \pm 83.4$ and $78.0 \pm 25.3$ licks for glucose and serine, respectively; $p<0.0005$, two-sample $t$ test; $t=5.4)$, KO mice consumed essentially the same amounts of both nutrients (165.5 \pm 56.2 and $212.2 \pm 87.7$ licks for glucose and serine, respectively; $p>0.4$ ). Thus, at least in tests in which the effects of postingestive factors on consumption are minimized, Trpm5 KO, unlike WT, mice do not express any preferences toward the orosensory properties of glucose solutions. 
A

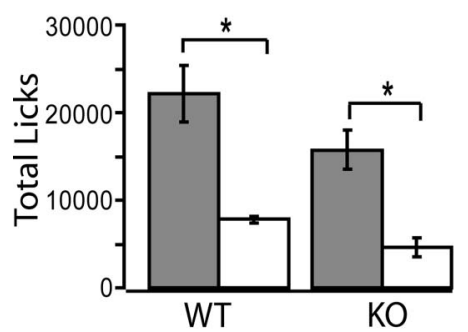

-Glucose 口L-Serine

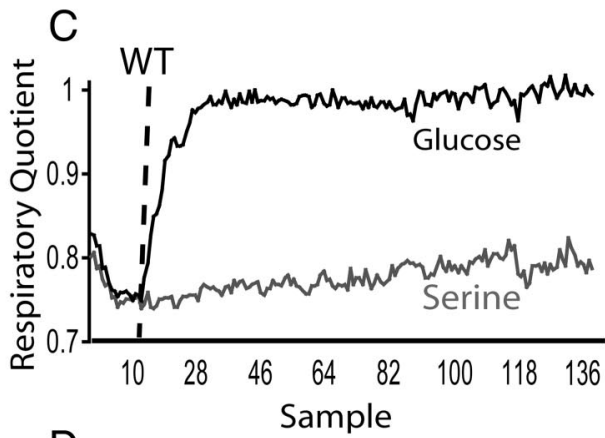

D

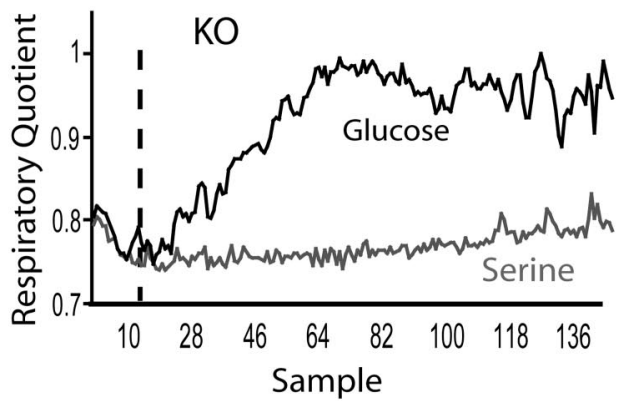

aGlucose sessions $\square$ L-Serine sessions **

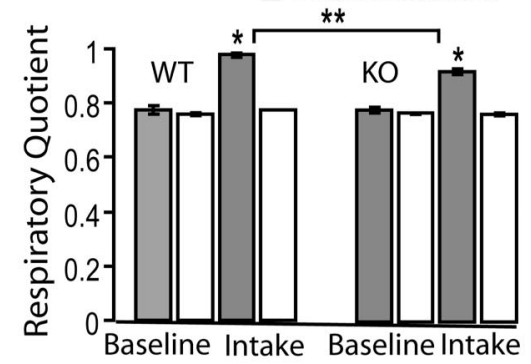

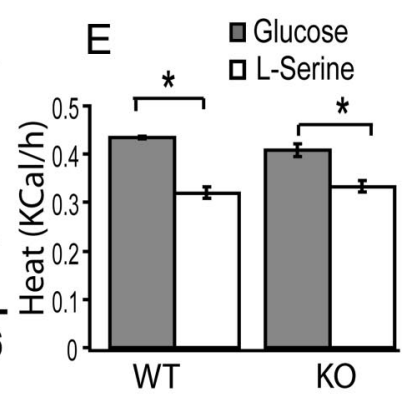

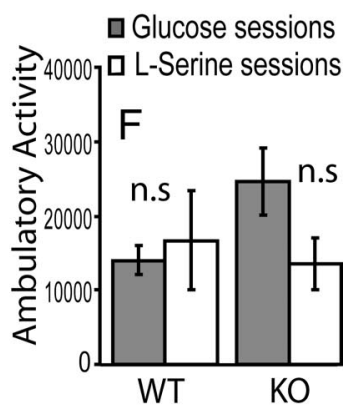

Figure 2. Indirect calorimetry measurements during nutrient intake monitoring in Trpm5 KO and WT mice. A, In agreement with the conditioning sessions, long-term $(21 \mathrm{~h})$ nutrient availability resulted in significantly higher levels of consumption of glucose versus serine solutions in both WT and K0 animals ( ${ }^{*} p<0.0009$; see Results). $\boldsymbol{B}$, Both WT and K0 animals displayed higher respiratory quotients during glucose versus serine sessions $\left({ }^{*} p<0.0003\right.$; see Results). However, WT mice displayed higher quotients during glucose sessions compared with $\mathrm{KO}$ mice ( ${ }^{* *} p<0.01$; see Results). $\boldsymbol{C}, \boldsymbol{D}$, Mean respiratory quotient value across mice of time courses for WT $(\boldsymbol{C})$ and $K O(\boldsymbol{D})$ mice. Vertical dotted lines represent the time point at which nutrients became available for the first of the four cages. $E$, Both WT and KO animals displayed higher heat production during glucose versus serine sessions $\left({ }^{*} p<0.0005\right.$; see Results). $\boldsymbol{F}$, No nutrient- or genotype-specific effects were detected on ambulatory activity.

Trpm5 KO mice develop preferences for glucose over amino acid solutions independently of taste quality and caloric load It remains to be resolved whether the overall increased consumption of glucose in WT mice is accounted for by the hedonics of taste or, alternatively, by postingestive factors acting in addition to taste hedonics. With this question in mind, we have applied a conditioning protocol in which animals are given the opportunity to associate the particular postingestive consequences of a solution with a sipper position in the behavioral cage (de Araujo et al., 2008) (see Materials and Methods). Briefly, serine (14.5

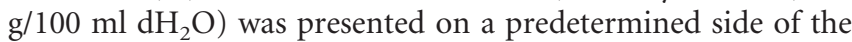
chamber for $3 \mathrm{~d}$ that were intercalated with 3 other days in which the glucose (isocaloric $14.5 \mathrm{~g} / 100 \mathrm{ml} \mathrm{dH}_{2} \mathrm{O}$ ) was presented on the opposite side of the chamber. Assignment of a solution to a particular side of the chamber was chosen based on preliminary behavioral tests such that side biases were factored out. After training, side preferences were tested in 10-min-long two-bottle water versus water postconditioning tests. The conditioning experiment involved the use of 14 initially naive mice (seven $\mathrm{KO}$, seven WT). The results were as follows (Fig. 1C,D). As expected, WT mice consumed significantly more glucose than serine during training sessions $(798.8 \pm 88.1$ and $277.9 \pm 26.2$ licks for glucose and serine, respectively; $p<0.000006$, two-sample $t$ test; $t=5.5$ ) (Fig. 1C). Unlike during short-term preference tests, KO mice showed significantly higher levels of glucose intake compared with serine during the conditioning sessions (433.2 \pm 47.3 and $205.6 \pm 27.3$ licks for glucose and serine, respectively; $p<0.002 ; t=3.02$ ) (Fig. $1 D)$, an effect we attribute to the specific postingestive effects associated with the solutions.

In agreement with the patterns observed above, during the posttraining two-bottle water versus water tests both $\mathrm{KO}$ and WT mice displayed increased preferences for the sipper positions previously associated with glucose availability. WT mice exhibited preference ratios significantly larger than 0.5 toward the glucose-associated sipper $(0.68 \pm 0.03$; one-sample $t$ test, $p<$ $0.002 ; t=5.0)$, as did $\mathrm{KO}$ mice $(0.65 \pm$ 0.05; $p<0.02, t=3.0$ ) (Fig. $1 E$ ). We have also verified that, in these same mice, substituting water for the glucose solution (keeping the sipper position fixed) attenuated of the effect described above, i.e., a relative decrease in preference toward that particular sipper. The results of this extinction test are described in supplemental Figure S1 (available at www.jneurosci.org as supplemental material).

Overall, the results of our behavioral tests provide strong evidence that choice patterns between glucose and L-amino acids are at least in part regulated by tasteindependent, postingestive factors. In addition, such factors did not depend on the total caloric value of the solution.

Taste-independent glucose intake is more closely associated with glucose oxidation than with blood glucose levels

We then set out to determine whether any metabolic parameters, more particularly those associated with glucose utilization, would reflect glucose intake levels in the absence of sweet taste signaling. Using metabolic cages equipped with contact lickometers (see Materials and Methods), we have performed indirect calorimetry measurements concomitant to monitoring ingestive (licking) behaviors in mice. Specifically, we have monitored the intake of glucose and serine solutions throughout the indirect calorimetry sessions. Each session was $\sim 24 \mathrm{~h}$ in duration. Foodand water-deprived ( $12 \mathrm{~h}$ ) naive animals (KO, $n=7$; WT, $n=7$ ) were subjected to two sessions each, separated by $24 \mathrm{~h}$ intervals. After a $3 \mathrm{~h}$ period of baseline measurements, animals were pre- 
sented with one bottle containing either $14.5 \%$ glucose or $14.5 \%$ serine solutions based on the concentrations used in the behavioral experiments. Each animal was presented with either one of the two solutions in alternate days, with presentation orders being counterbalanced across animals.

In agreement with the results obtained with our conditioning protocol, we found that both WT and Trpm5 KO animals consumed significantly higher amounts of glucose compared with serine (two-way ANOVA, $p<0.03$ for both nutrient and genotype main effects but $p>0.44$ for interaction). In fact, twosample post hoc $t$ tests reveal that both WT and KO animals consumed significantly more glucose compared with serine (WT: $22,160 \pm 3200$ licks for glucose vs $7807 \pm 412$ for serine, $p<$ 0.001 , paired $t$ test within animals; KO: $15,758 \pm 2251$ vs $4601 \pm$ 1105, $p<0.0008$ ) (Fig. $2 A$ ).

We have monitored the respiratory quotient values $\left(\mathrm{VCO}_{2} /\right.$ $\mathrm{VO}_{2}$; see Materials and Methods) during these sessions. As expected, glucose sessions were associated with significantly higher respiratory quotient values $(\sim 1.0)$, an indication of preferential use of glucose as substrate for oxidation. A repeated-measures two-way ANOVA revealed significant effects of nutrient $(p<$ $0.0001)$ (Fig. $2 B$ ) and genotype $(p<0.0003)$ on substrate oxidation, showing that genotype influenced the respiratory quotient values as demonstrated by a significant nutrient $\times$ genotype $(p<$ 0.001 ). However, direct post hoc $t$ tests revealed that both WT and KO displayed significantly higher respiratory quotient values during glucose compared with serine sessions (WT: $0.97 \pm 0.00$ for glucose vs $0.77 \pm 0.00$ for serine sessions, $p<7 \times 10^{-7}$ within-subject paired $t$ test; KO: $0.92 \pm 0.01$ vs $0.76 \pm 0.00, p<$ 0.00006 ) (the time courses of these responses are shown in Fig. $2 C, D)$. Moreover, no effects of nutrient or genotype were found during the baseline periods ( $p>0.25$ and $p>0.48$, respectively). Therefore, the genotype-related differences in respiratory quotient were attributable primarily to the different levels of intake associated with each genotype.

The above findings were supplemented by the measurement of heat production during nutrient intake. A repeated-measures two-way ANOVA revealed a significant effect of nutrient $(p<$ $0.0001)$ (Fig. $2 E$ ), but not genotype $(p>0.5)$, on thermogenic responses. No effects of nutrient or genotype were found for the baseline periods. In fact, direct post hoc $t$ tests reveal that both WT and $\mathrm{KO}$ displayed significantly higher heat production values during glucose compared with serine sessions (WT: $0.43 \pm 0.00$ $\mathrm{kcal} / \mathrm{h}$ for glucose vs $0.32 \pm 0.01$ for serine sessions, $p<5 \times 10^{-5}$ within-subject paired $t$ test; KO: $0.40 \pm 0.01$ vs $0.33 \pm 0.01$, $p<0.0005)$.

Finally, we also analyzed ambulatory activity displayed by animals during the indirect calorimetry sessions. We found no significant effects attributable to either nutrient or genotype (ANOVA, $p>0.3$ for all factors) (Fig. $2 F$ ). Overall, our indirect calorimetry data suggest that glucose oxidation, as expressed by higher respiratory quotient values, reflected the amounts of glucose consumed in each case.

We have also analyzed the extent to which other metabolic indexes of glucose metabolism, namely blood glucose and liver glycogen levels, are associated with sweet-taste-independent glucose intake. More precisely, we determined the blood glucose and liver glycogen levels from food- and water-deprived (15 h) mice exposed to 1-h-long behavioral sessions in which glucose or serine solutions were consumed freely from a single spout. Mice from both genotypes were divided in three groups representing the different physiological conditions, named "fasted" (no intake; KO, $n=5$; WT, $n=5$ ), "glucose" ( 1 h 14.5\% glucose intake;
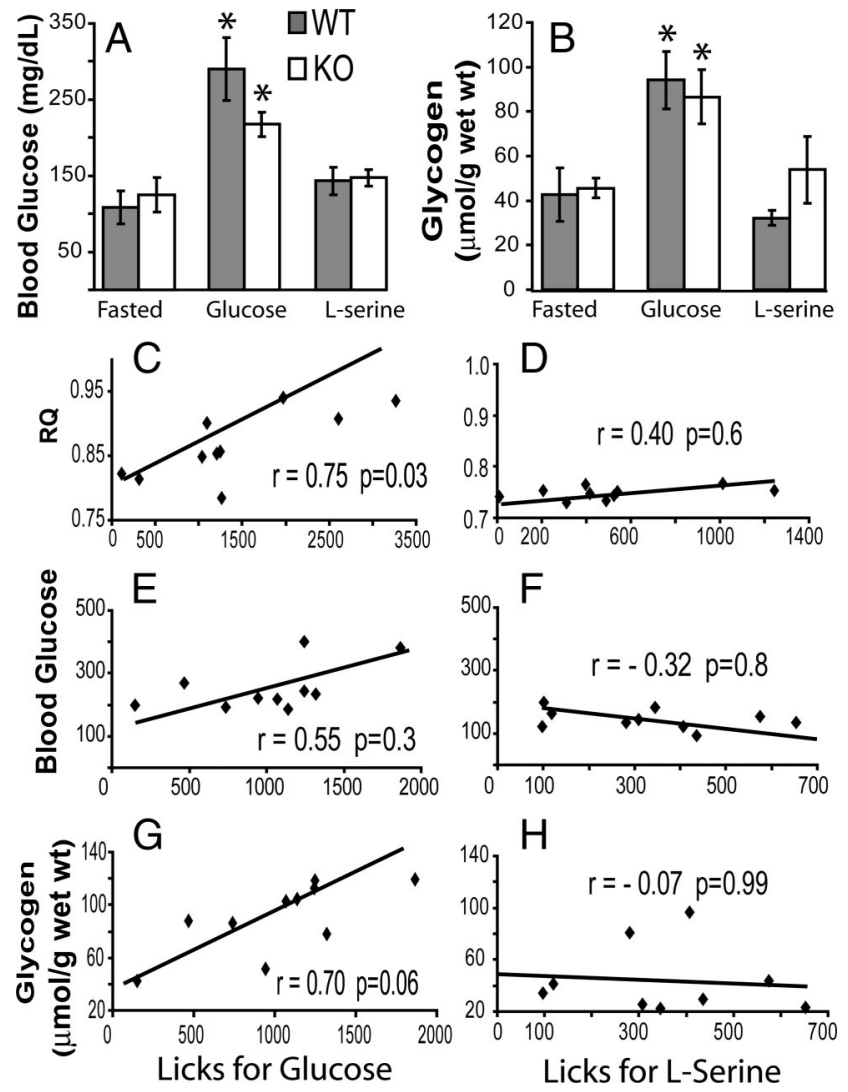

Figure 3. Glucose intake is more closely associated with glucose oxidation than with blood glucose levels. A, Blood glucose levels (in milligrams per deciliters) measured in WT and Trpm5 KO animals after food and water deprivation (Fasted), 1-h-long glucose intake sessions (Glucose), or 1-h-long serine intake sessions (t-serine). Blood glucose levels were significantly higher after glucose intake compared with both serine intake sessions and fasting, in both $\mathrm{KO}$ and WT animals ( ${ }^{*} p<0.05$ with respect to all other conditions, two-sample $t$ test). $\boldsymbol{B}$, Liver glycogen levels (expressed in glucosyl units micromoles per grams wet weight) were measured in WT and Trpm5 $\mathrm{KO}$ animals after food and water deprivation (Fasted), 1-h-long glucose intake sessions (Glucose), or 1-h-long serine intake sessions (L-serine). Liver glycogen levels were significantly higher after glucose intake compared with both serine intake sessions and fasting, in both $\mathrm{KO}$ and WT animals ( ${ }^{*} p<0.05$ with respect to all other conditions, two-sample $t$ test). $\boldsymbol{C}-\boldsymbol{H}$, Scatter plots showing the association between glucose metabolism parameters and nutrient intake. The corresponding regression lines are shown in each case along with the computed values pairwise (Pearson's) correlation coefficients and associated $p$ values. Correlations are shown between number of licks for glucose and the corresponding RQ values $(\boldsymbol{C})$, number of licks for serine and the corresponding respiratory quotient values $(\boldsymbol{D})$, licks for glucose and the corresponding blood glucose levels $(\boldsymbol{E})$, licks for serine and the corresponding blood glucose levels $(\boldsymbol{F})$, licks for glucose and the corresponding liver glycogen levels $(\boldsymbol{G})$, and licks for serine and the corresponding liver glycogen levels $(\boldsymbol{H})$. Note that the strongest association found was between glucose intake and glucose oxidation ( $\boldsymbol{C}$.

$\mathrm{KO}, n=5$; WT, $n=5$ ), and "serine" ( $1 \mathrm{~h} 14.5 \%$ serine intake; $\mathrm{KO}, n=5$; WT, $n=5$ ). For the blood glucose data, a two-way physiological state $\times$ genotype ANOVA revealed a strong effect of physiological state $(p<0.0002)$, but not of genotype $(p>$ 0.27 ) or interactions $(p>0.25)$, on blood glucose levels. In fact, whereas fasted glucose levels were $108.6 \pm 21.6$ and $124.8 \pm 22.3$ $\mathrm{mg} / \mathrm{dl}$ for WT and KO mice, respectively, levels after $1 \mathrm{~h}$ glucose intake were $290.4 \pm 41.1$ and $217.4 \pm 16.1 \mathrm{mg} / \mathrm{dl}$ for WT and KO mice, respectively, and finally, after $1 \mathrm{~h}$ serine intake, they were $143.0 \pm 17.9$ and $147.2 \pm 10.4 \mathrm{mg} / \mathrm{dl}$ for WT and $\mathrm{KO}$ mice, respectively (Fig. 3A). Post hoc two-sample $t$ tests further revealed that blood glucose levels increased significantly after glucose intake compared with both the fasted $(t=3.96 ; p<0.001)$ and the post-serine $(t=4.17 ; p<0.0005)$ states. Finally, and in agree- 
ment with the calorimetric data, no significant differences were found in blood glucose levels between fasted and post-serine states $(t=0.52 ; p=0.6)$.

Analogously, a two-way physiological state $\times$ genotype ANOVA on the liver glycogen data (expressed in glucosyl units micromoles per grams wet weight; see Materials and Methods) revealed a strong effect of physiological state $(p<0.0003)$ but not of genotype $(p>0.5)$ or interactions $(p>0.39)$. In fact, whereas fasted glycogen levels were $42.6 \pm 11.9$ and $45.6 \pm 4.5$ $\mu \mathrm{mol} / \mathrm{g}$ for WT and KO mice, respectively, levels after $1 \mathrm{~h}$ glucose intake were $94.1 \pm 13.0$ and $86.5 \pm 12.2 \mu \mathrm{mol} / \mathrm{g}$ for WT and $\mathrm{KO}$ mice, respectively, and finally, after $1 \mathrm{~h}$ serine intake, they were $32.1 \pm 3.3$ and $54.0 \pm 15.0 \mu \mathrm{mol} / \mathrm{g}$ for WT and KO mice, respectively (Fig. 3B). Post hoc two-sample $t$ tests further revealed that liver glycogen levels increased significantly after glucose intake compared with both the fasted $(t=4.43 ; p<0.004)$ and the post-serine $(t=4.0 ; p<0.007)$ states. Finally, and in agreement with the blood glucose data, no significant differences were found in glycogen levels between the fasted and post-serine states $(t=$ $-0.14 ; p=0.8$ ).

Next, we set out to compare the association strengths between total number of licks to glucose and the glucose metabolic parameters (blood glucose, glycogen, or respiratory quotients). To make the calorimetric sessions comparable with those sessions in which blood glucose and liver glycogen were measured, we extracted from the calorimetric sessions the respiratory quotient and lick values corresponding to the first hour of the experiment based on 10 (WT, $n=5$; KO, $n=5$ ) animals (note that, in all cases, the deprivation period was $15 \mathrm{~h}$ ).

We calculated the pairwise correlation coefficients (Pearson's $r$; see Materials and Methods) between the glucose metabolism parameters and the total number of licks for each case. We found a significant association between respiratory quotient values and glucose (pairwise coefficient $r=0.75$, Bonferroni's corrected for multiple comparisons, $p=0.03$ ) (Fig. $3 C)$, but not serine ( $r=$ $0.4 ; p=0.6$ ) (Fig. $3 D$ ), intake. However, and rather surprisingly, blood glucose levels were considerably less strongly associated with glucose intake $(r=0.55 ; p=0.3)$ (Fig. $3 E)$, as in the case for serine $(r=-0.32 ; p=0.8)$ (Fig. $3 F)$. Glycogen levels were moderately associated with glucose $(r=0.70 ; p=0.06)($ Fig. $3 G)$, but not serine $(r=0.07 ; p=0.9)$ (Fig. $3 H$ ), intake. Finally, we found no significant differences in blood urea nitrogen levels between $\mathrm{KO}$ and WT chow-fed mice $(23.28 \pm 2.47$ vs $24.85 \pm 2.15 \mathrm{mg} / \mathrm{dl}$, respectively; two-sample $t$ test, $p=0.64$ ), suggesting that no major alterations in amino acid metabolism and/or protein digestion are associated with the deletion of the Trpm 5 gene in mice.

Together, our glucose metabolism data strongly indicate that the ability of a nutrient to increase the rate of utilization of glucose, rather than increasing blood glucose per se, is closely associated with its reinforcing potency.

\section{Orosensory factors did not contribute to the increased glucose intake levels during long-term sessions}

It is also possible that the increased intake levels associated with glucose solutions are accounted for by residual taste sensitivity and/or additional orosensory aspects of the solutions (e.g., odor, texture). To rule out this possibility, we used 10-min two-bottle preference control tests on the same animals exposed to the longterm calorimetry sessions (WT, $n=7$; KO, $n=7$ ), such that preference tests were performed immediately after animals completed the indirect calorimetry experiments. Trpm $5 \mathrm{KO}$ mice displayed increased preferences for glucose compared with serine solutions during the longer-term indirect calorimetry sessions
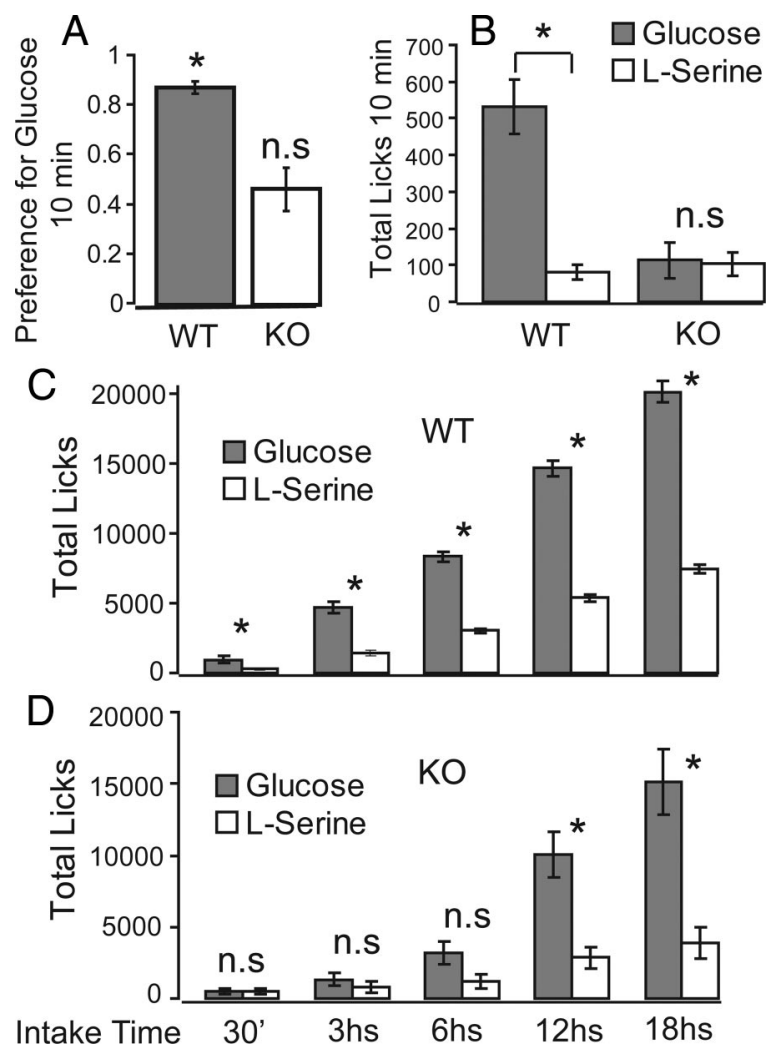

Figure 4. Trpm5 K0, but not WT, mice fail to display increased preferences toward glucose solution during post-calorimetry two-bottle preference tests. WT and KO animals previously presented for $21 \mathrm{~h}$ with glucose or serine in different indirect calorimetry sessions were exposed to post-calorimetry 10 min glucose versus serine preference tests. $A$, Preference ratios, significantly above 0.5 , were associated with WT but not K0 mice ( $\left.{ }^{*} p<0.004\right)$. $B$, Glucose intake levels during preference tests were significantly higher compared with serine in WT but not $K 0$ mice ( ${ }^{*} p<0.0002$ ). C, WT mice display higher levels of glucose intake compared with serine within 30 min of onset of nutrient availability ( ${ }^{*} p<0.04$ at least). $D$, Conversely, such a pattern emerged, on average, only after $6 \mathrm{~h}$ in $\mathrm{KO}$ mice ( ${ }^{*} p<0.003$ ). For details, see Results.

( $\sim 21 \mathrm{~h}$ of continuous access to nutrients). Accordingly, we reasoned that, if $\mathrm{KO}$ mice made use of gustatory or other orosensory cues to guide their increased levels of glucose intake, then they would once again make use of such cues to maximize the intake of the preferred glucose solution in detriment of the less preferred serine solution. The results of the post-calorimetry 10-min twobottle preference tests were as follows. When compared with the indifference ratio of 0.5 , we found that, whereas WT animals displayed a strong attraction for glucose solutions (preference ratio of $0.87 \pm 0.02$; one-sample $t$ test against $0.5, t=3.58, p<$ $0.004), \mathrm{KO}$ mice showed an obvious indifference between the two solutions (preference ratio of $0.46 \pm 0.08 ; t=-0.12 ; p>0.9$ ) (Fig. 4A). Such indifference becomes even more evident when one considers the total number of licks produced during these post-calorimetry preference tests: whereas WT mice licked significantly more times to glucose solutions compared with serine solutions $(531 \pm 74$ and $79 \pm 20$ licks for glucose and serine, respectively; paired two-sample $t$ test, $t=6.3 ; p<0.0002$ ) (Fig. $4 B), \mathrm{KO}$ animals produced virtually the same number of licks for both solutions ( $113 \pm 47$ and $103 \pm 32$ licks, respectively; $t=0.2$; $p>0.8$ ). A second line of evidence showing that orosensory cues, if any, did not influence intake levels relates to the temporal patterns of intake observed during the calorimetry sessions. On one hand, WT animals rapidly displayed higher intake levels of glucose compared with serine, more precisely within $30 \mathrm{~min}$ of nu- 
trient availability onset (within-animal paired $t$ test; at least $p<$ 0.04 for all $30 \mathrm{~min}, 3 \mathrm{~h}, 6 \mathrm{~h}, 12 \mathrm{~h}$, and $18 \mathrm{~h}$ periods) (Fig. 4C). However, in $\mathrm{KO}$ animals, such pattern emerged only after $6 \mathrm{~h}$ of nutrient availability $(p>0.9, p>0.39$, and $p>0.06$ for $30 \mathrm{~min}$, $3 \mathrm{~h}$, and $6 \mathrm{~h}$, respectively, but $p<0.003$ for both 12 and $18 \mathrm{~h}$ periods) (Fig. $4 D$ ). Together, the results above strongly indicate that Trpm5 KO animals did not make use of residual gustatory sensitivity or other orosensory cues to guide their behavior preferences toward glucose solutions. In summary, lacking preferences for glucose versus amino acids during short-term, but not long-term, tests was the only essential behavioral difference observed in this study between $\mathrm{KO}$ and WT mice.

\section{Intragastric infusions of glucose and serine produce nutrient-specific dopamine release patterns}

Next, we investigated the question of which neural circuits could underlie the observed preferences for sugars in the absence of sweet taste signaling. We focused on the mesolimbic dopamine system given its central role in the generation of motivated feeding behaviors. We have hypothesized that nutrient-specific activation of brain dopamine centers can be initiated by direct stimulation of the gastrointestinal tract. We measured extracellular dopamine levels in the mouse striatum during a procedure of nutrient delivery that bypasses oral stimulation, i.e., during intragastric infusions of nutrient solutions. We opted for intragastric infusions as a way to rule out nonspecific effects, including differential gastric distention or discrepancies in caloric load. We demonstrate the behavioral relevance of the intragastric infusion model by showing that animals implanted with intragastric catheters will develop preferences for water sipper positions in which licks to water were associated with intragastric infusions of glucose compared with water sippers associated with serine infusions. The experiment makes use of WT mice implanted with gastric catheters $(n=5)$. An infusion pump holding a syringe containing the nutrient was connected to the gastric catheter and placed under control of the behavioral chamber, so that each lick for water detected by the lickometer immediately triggered a 3-slong infusion of the nutrient into the stomach (at a rate of 10 $\mu \mathrm{l} / \mathrm{min}$ ). The experiment was designed to match with exactitude the conditioning protocol described above, in that presentation of a water sipper on one side of the cage was associated with glucose gastric infusions and with L-serine gastric infusions on the opposite side of the chamber. Therefore, one single bottle associated with a particular side of the cage (and one single infused nutrient) were used per conditioning session. The results were as follows. A two-way repeated-measures (infused nutrient $\times$ conditioning day) ANOVA on the number of licks for water revealed significant infused nutrient $(p<0.03)$ and conditioning day $(p<0.005)$ main effects on water intake. In fact, during the glucose infusion sessions, WT animals produced $27.7 \pm 3.5$ licks for water compared with $21.5 \pm 2.5$ licks during the L-serine infusion sessions (Fig. $5 A$ ). Next, we verified whether these behavioral patterns depended on conditioning day, which would be consistent with the action of nutrient-specific postingestive effects on ingestive behaviors. In fact, we found that the effect above was entirely accounted for by the number of licks for water produced during the last two conditioning sessions: in the first glucose infusion conditioning session, animals produced only $11.0 \pm 1.7$ licks for water, which was not significantly different from the $13.4 \pm 3.0$ licks for water produced during the first L-serine infusion session $(t=-0.7 ; p>0.46)$. However, when assessing the last two glucose conditioning sessions in combina-
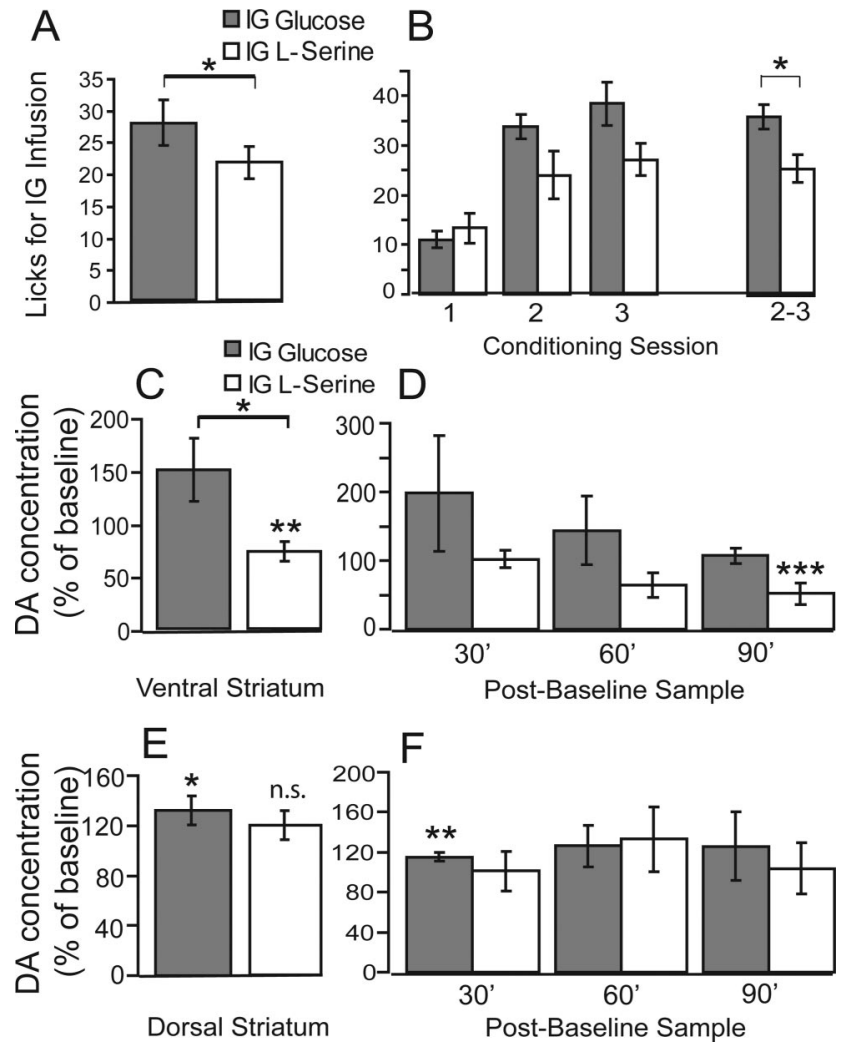

Figure 5. Intragastric (IG) infusions of glucose and serine induce differential brain dopamine responses. $\boldsymbol{A}, \boldsymbol{B}$, An infusion pump holding a syringe containing a given nutrient was connected to the gastric catheter and placed under control of the behavioral chamber, so that every lick for water detected by the lickometers immediately triggered a 3-s-long infusion of the nutrient into the stomach (at a rate of $10 \mu \mathrm{l} / \mathrm{min}$ ). The positions of water bottles in the cage were associated with infusion of one specific nutrient. $\boldsymbol{A}$, Across conditioning sessions, animals produced significantly more licks for water during glucose infusion sessions compared with serine infusion sessions ( $\left.{ }^{*} p<0.04\right)$. $\boldsymbol{B}$, The effect depended on conditioning day, because the difference in water intake between glucose and serine infusion sessions was significant for sessions 2 and 3 combined but not for session $1\left({ }^{*} p<0.02\right)$. C, Overall percentage changes produced by glucose and serine intragastric infusions. In the nucleus accumbens, glucose infusions were associated with significantly higher levels of extracellular dopamine when directly compared with serine infusions ( ${ }^{*} p<0.03$, two-sample $t$ test). In addition, significant decreases in dopamine levels were observed after serine infusions $\left({ }^{* *} p<0.02\right.$, one-sample $t$ test against $100 \%$ ). D, Whereas glucose infusions were consistently associated with increased dopamine levels across samples, relative decreases produced by serine infusions were marked in particular at the third sample ( $\left.{ }^{* * *} p<0.04\right)$. $\boldsymbol{E}$, In dorsal striatum, significant increases in dopamine levels were associated with glucose $\left({ }^{*} p=0.009\right.$, one-sample $t$ test against $\left.100 \%\right)$, but not serine $(p<0.09)$, infusions. $\boldsymbol{F}$, Across samples, significant increases in dopamine levels were observed only during glucose infusions at 30 min after infusion onset $\left({ }^{* *} p<0.04\right.$, one-sample $t$ test against 100\%).

tion, we found that animals produced $36.1 \pm 2.4$ licks for water compared with $25.6 \pm 2.7$ licks during the equivalent L-serine infusion sessions. This difference was significant (paired twosample $t$ test, $t=2.86 ; p<0.02$ ) (Fig. $5 B$ ). Therefore, direct infusion of glucose and $\mathrm{L}$-serine into the stomach did not abolish nutrient-specific effects on ingestive behavior. We interpret these results as implying that Trpm $5 \mathrm{KO}$ mice can be used to ablate the orosensory aspects of L-amino acids while preserving their sensitivity to their specific postingestive actions.

We then assessed the effects produced by intragastric infusions of glucose or serine on accumbal dopamine levels in mice implanted with both gastric catheters and microdialysis probes $(n=5)$. In these experiments, $14.5 \%$ (i.e., the same concentration used in behavioral and indirect calorimetry sessions) solu- 
tions of either glucose or serine were infused for $90 \mathrm{~min}$ (10 $\mu \mathrm{l} / \mathrm{min}$ ) after a no-injection baseline period of 30-90 min. Samples were collected every $30 \mathrm{~min}$. We then compared the changes in extracellular dopamine levels (relative to baseline levels) produced by the glucose and serine infusions. We found that intragastric infusions of glucose or serine induce nutrient-specific changes in dopamine levels in the nucleus accumbens. More precisely, intragastric infusions of glucose produced significantly higher levels of dopamine release in accumbens compared with isocaloric infusions of serine ( $149.7 \pm 29.3$ vs $72.7 \pm 9.3 \%$ change in dopamine levels relative to preinfusion baseline for glucose and serine, respectively; within-subjects paired two-sample $t$ test, $t=2.28$; $p<0.03$ ) (Fig. $5 C$ ). We stress in particular the significant decrease in dopamine levels in accumbens after serine infusions (one-sample $t$ test against $100 \%, t=-2.6$; $p<0.02$ ), an effect that we relate to the lower levels of serine intake in $\mathrm{KO}$ animals.

We verified whether these nutrient-specific patterns were consistent across samples. A two-way repeated-measures nutrient $X$ sample ANOVA reveals a significant effect of nutrient $(p<$ $0.04)$, but not of sample ( $p=0.2)$, on changes in dopamine levels throughout the experiment (Fig. 5D). We do notice, however, that, whereas glucose infusions were consistently associated with stable dopamine levels across samples, the relative decreases produced by serine infusions intensified as sessions progressed. In particular, dopamine levels measured from the third sample (90 min after infusion onset) were $51.5 \pm 16.1 \%$ of baseline levels $(t=-2.99 ; p<0.04)$, whereas, despite a trend toward decrease levels throughout the session, no such robust decreases were associated with the first two samples $(102.1 \pm 13.1 \%, p=0.88$ and $64.4 \pm 18.0 \%, p=0.12$, respectively) (Fig. $5 D$ ).

Because dopamine signaling in dorsal striatum has also been implicated in feeding behavior (see Discussion), we have in addition assessed the effects produced by intragastric infusions of glucose and serine on dorsal striatum dopamine levels $(n=5)$. Interestingly, the patterns of dopamine release in dorsal striatum during intragastric nutrient infusions differed from those observed in the ventral areas. In fact, whereas no significant decreases in dopamine levels were observed during serine infusions (one-sample $t$ test against $100 \%, t=1.7 ; p=0.09$ ), significant increases were associated with glucose infusions $(t=2.86$; $p<$ 0.009 ) (Fig. 5E). Differences with respect to ventral regions are further evidenced by an analysis of the temporal dopamine release patterns. In fact, the observed dopamine-level increases in dorsal regions during glucose infusions are accounted for mainly by changes occurring within $30 \mathrm{~min}$ of infusion onset: whereas the first (at $30 \mathrm{~min}$ ) dopamine sample was associated with moderate, although statistically significant, increases in dopamine levels (115.4 $\pm 4.2 \%$; one-sample $t$ test against $100 \%, t=3.0 ; p<$ 0.04) (Fig. 5F), no such effect was observed for the remaining samples obtained during glucose infusions ( $126.1 \pm 20.9 \%, p=$ 0.33 ; and $126.0 \pm 34.0 \%, p=0.39$ ). Finally, and as expected, no significant changes in dorsal striatum dopamine levels were observed for any of the samples obtained during serine infusions $(101.2 \pm 19.9 \%, p=0.66 ; 132.9 \pm 32.2 \%, p=0.23$; and $103.8 \pm$ $25.2 \%, p=0.53$ ) (Fig. 5F).

Our microdialysis studies thus provide evidence that nutrientspecific dopamine release can be initiated during direct stimulation of the gastrointestinal tract, an effect whose properties depended on the striatal region (i.e., ventral vs dorsal) being sampled.

\section{Differential absorption of nutrients and/or gut-derived factors did not play a major role during taste-independent preferences for glucose versus serine}

Regarding our results presented so far, it must be noted that the amounts of glucose and serine that were absorbed into the circulation during the experiments have not been determined. Therefore, nutrient-specific differences in absorption is one possible confound associated with our interpretation of the data. In addition, nutrient-specific release of nutrient-controlling gut hormones (e.g., ghrelin) (Tschöp et al., 2000) might also have played a major role in shaping both the behavioral and dopaminergic responses. We have therefore directly addressed this issue by performing additional experiments in which, once again, animals licked a water spout to obtain either glucose or serine infusions but this time making use of jugular rather than gastric catheters. All other aspects of the experiment were kept identical to those used during the experiments involving gastric catheters presented above. Coupling water licks to intravenous infusions of nutrients should therefore ascertain that equal amounts of glucose and serine reach the circulation every time a bolus of nutrient is infused into the catheter.

We hypothesized that the results obtained using jugular catheters would be consistent with those obtained using gastric catheters, in that animals would lick significantly more times to water when receiving intravenous infusions of glucose compared with when receiving intravenous infusions of serine. In fact, we have monitored the overall number of licks produced during the entire session, and, as hypothesized, we observed that WT $(n=10)$ mice licked significantly more times to water during glucose compared with serine intravenous sessions $(449 \pm 87$ and $296 \pm 78$ water licks for glucose and serine, respectively; within-subject difference, $153.2 \pm 66.7$ licks; one-tailed paired $t$ test, $t=2.29 ; p=$ 0.02 ) (Fig. 6A).

We have in addition quantitatively verified whether coupling licks to water with intravenous nutrient infusions were equivalent as a procedure to coupling licks to intragastric infusions. A two-way nutrient $X$ infusion method ANOVA was performed on the number of licks to water observed during both the intragastric and intravenous sessions. We have found a strong effect of nutrient $\left(F_{(1,16)}=11.6 ; p<0.004\right)$ but not of infusion method $\left(F_{(1,16)}=\right.$ $0.19 ; p=0.6)$ or interaction $\left(F_{(1,16)}=0.47 ; p=0.5\right)$, on number of licks to water. Therefore, because there were no major differences associated with gastric versus intravenous infusions, we conclude that the taste-independent differential responses to glucose and serine are not primarily accounted for by differential absorption rates or secretion of gut-derived factors, but rather by direct actions of nutrients on metabolism.

\section{Disrupting glucose metabolism inhibits dopamine release in dorsal striatum}

To address the issue of whether the metabolism of glucose is relevant or not to nutrient-specific differences in dopamine release, we have designed a new experiment in which wild-type mice $(n=5)$ were fitted with a microdialysis probe in the striatum as well as with a jugular venous catheter. After measuring baseline dopamine levels, we have infused a bolus of the antimetabolic glucose analog 2-DG via the jugular catheter for 6 min and monitored dopamine levels for $1 \mathrm{~h}$ after the injection (four samples). This was then followed by an intravenous glucose infusion lasting for $10 \mathrm{~min}$, after which two samples were collected (30 $\mathrm{min})$.

We reasoned that, if glucose metabolism is indeed relevant for the increased brain dopamine levels observed in striatum during 

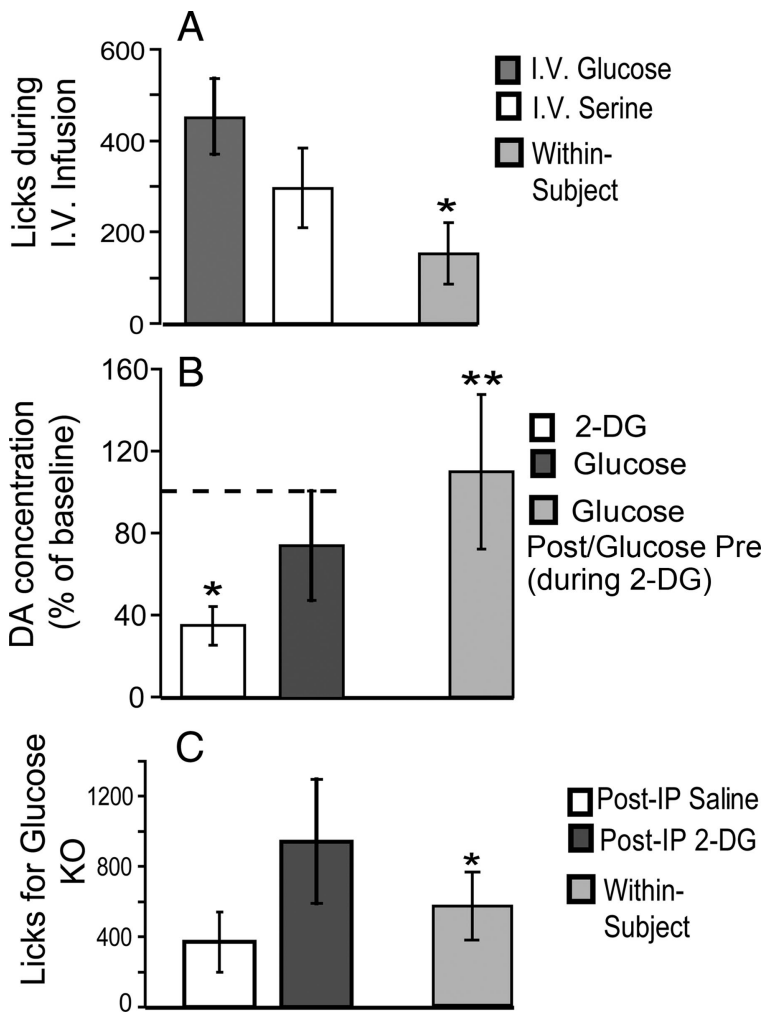

Figure 6. Intravenous infusions of glucose and serine induce differential behavioral responses in the absence of taste signaling, and inhibition of glucose oxidation decreases dopamine concentration levels in striatum. $\boldsymbol{A}$, An infusion pump holding a syringe containing a given nutrient was connected to a jugular catheter and placed under control of the behavioral chamber, so that every lick for water detected by the lickometers immediately triggered a 3-s-long intravenous infusion of the nutrient (at a rate of $10 \mu \mathrm{l} / \mathrm{min}$ ). Animals produced significantly more licks for water during glucose infusion sessions compared with serine infusion sessions $\left({ }^{*} p<0.03\right.$ for within-subject glucose-serine difference, paired one-tailed two-sample $t$ test). $\boldsymbol{B}$, Infusing the antimetabolic glucose analog 2-DG via a jugular catheter resulted in a significant decrease in dopamine concentration levels in dorsal striatum $\left({ }^{*} p<0.007\right.$, one-sample $t$ test against $100 \%$ preinfusion levels). This suppressive effect was then reversed within 30 min via a 10 min intravenous glucose infusion. Whereas glucose infusions promoted a reinstatement of dopamine concentration to levels similar to those of baseline samples, it represented a robust increase in dopamine levels with respect to the samples collected immediately after 2-DG infusion (109.9 $\pm 37.6 \%$ increase in overall dopamine concentration; ${ }^{* *} p=0.03$ compared with $0 \%$ increase). $\boldsymbol{C}$, Consistent with the dopamine measurements shown in $\boldsymbol{B}$, presentation of glucose after an intraperitoneal injection of 2-DG resulted in significantly higher levels of glucose intake compared with after a vehicle injection in $\mathrm{KO}$ animals during 30-min-long sessions $\left({ }^{*} p<0.03\right.$ for within-subject glucose-serine difference, paired two-sample $t$ test). Therefore, glucose solutions were attributed a higher reward value when contributing to restore glucose oxidation in sweet-insensitive animals, as would be predicted from the equivalent changes in dopamine levels shown in $\boldsymbol{B}$.

glucose ingestion, then an infusion of 2-DG should result in significant decreases in extracellular dopamine levels and that such inhibitory effect on dopamine release must be reversed or at least attenuated by a subsequent intravenous glucose infusion that would contribute to restore normal rates of glucose oxidation.

The results of this experiment were as follows. Intravenous infusions of 2-DG at the smallest dose known to produce significant behavioral effects in C57BL/6 mice ( $400 \mathrm{mg} / \mathrm{kg}$ ) (Lewis et al., 2006) produced a robust decrease in extracellular dopamine levels in striatum $(34.7 \pm 9.5 \%$ dopamine concentration of initial baseline; one-sample $t$ test against baseline concentration level of $100 \%, t=-6.8 ; p<0.007$ ) (Fig. 6B). In addition, and also consistent with our prediction, the subsequent infusion of glucose resulted in a reversal of this effect, with overall dopamine concentration levels reaching $74.5 \pm 26.7 \%$ of the original baseline levels within $30 \mathrm{~min}$, such that these post-2-DG glucose infusions resulted in extracellular dopamine levels that did not differ from the original baseline levels $(t=-0.95 ; p=0.41)$ (Fig. $6 \mathrm{~B})$. None of those effects were observed after control injections with vehicle (all $p>0.3$ ).

Importantly, we observed that glucose infusions produced a striking increase in striatal dopamine levels when the comparison is made with respect to the levels observed after 2-DG infusions. In fact, within $30 \mathrm{~min}$, glucose infusions produced a $109.9 \pm$ $37.6 \%$ increase in overall dopamine concentration levels with respect to the samples collected immediately after 2-DG injection $(t=2.92 ; p=0.03)$ (Fig. $6 B$, rightmost bar). Note that interference with gut signals was minimized in this experiment because glucose infusions were made via a vascular catheter.

\section{Glucose solutions acquire higher reward value when contributing to reinstate glucose oxidation}

We have assumed throughout this study that relative changes in extracellular dopamine levels reflect the reinforcing potency of a nutrient even in the absence of taste receptor signaling. Therefore, we are now led to conclude that ingesting glucose after an injection of 2-DG must significantly increase the reward value of glucose compared with after a vehicle injection, even in sweetinsensitive Trpm5 knock-out animals. In other words, we hypothesized that glucose acquires a superior reward value when counteracting the effects of inhibiting glucose oxidation.

We tested this hypothesis by measuring glucose intake in $\mathrm{KO}$ mice after an intraperitoneal injection of either 2-DG (400 mg/ $\mathrm{kg}$, the same dose used in the microdialysis experiment) or vehicle (saline). After the injections, animals were exposed to a 30min one-bottle session in which they were offered ad libitum access to glucose $(14.5 \%$, the same concentration used in the microdialysis experiment and throughout this study). Whereas after vehicle intraperitoneal injections KO mice produced $369 \pm$ 172 licks to glucose, after 2-DG injections these same animals produced $942 \pm 354$ licks to glucose, a significant difference in intake levels (within-subject difference, $573 \pm 195$ licks for 2-DG-saline; paired two-sample $t$ test, $t=2.92 ; p<0.025$ ) (Fig. $6 C)$. To control for possible order effects, we note that a second session associated with vehicle injection produced, as expected, significantly lower levels of glucose intake compared with the preceding $2-\mathrm{DG}$ session $(p<0.01)$. Therefore, within $30 \mathrm{~min}$ of 2-DG administration, glucose acquired higher reward value when reinstating glucose oxidation levels, a finding that was entirely consistent with the dopamine measurements after 2-DG and glucose infusions described above.

\section{Discussion}

In this study, we have shown that animals will ingest higher quantities of, and develop preferences for, the carbohydrate glucose versus an isocaloric amino acid, even when unable to detect the distinctive flavor qualities intrinsic to each nutrient. Our indirect calorimetry experiments, moreover, show that these higher intake levels were closely associated with glucose oxidation levels, even more markedly than with increases in blood glucose. Finally, our microdialysis studies showed that different food sources can exert nutrient-specific effects on brain dopamine systems independently of orosensory inputs. These differential metabolic and gut-initiated dopamine responses strongly support the existence of nongustatory factors regulating preferences for glucose over amino acids.

In our behavioral studies, we made use of the fact that the Trpm 5 knock-out mice of the strain used here are unable to detect 
sweet, and most forms of L-amino acid, taste as was shown previously (Zhang et al., 2003). In a second Trpm5 knock-out strain described by Damak et al. (2006), residual sensitivity to highconcentration sucrose and umami solutions has been reported at both behavioral and cranial nerve levels. However, the two strains were generated according to different targeted mutations of the Trpm 5 gene. In fact, Damak et al. (2006) observe that the dissimilar phenotypes displayed by the two strains might result from the different gene deletions used in each case. In any event, the central fact to be retained here is that the strain used in our study did not display any residual sensitivity to sugars or to the amino acid solutions used in our tests, in conformity with previous findings (Zhang et al., 2003). We also stress that no specific functional role is being specifically assigned to the Trpm5 gene itself, which implicates that the comparisons performed against wild-type animals must be considered as comparisons between two different strains, as has been done previously (Sclafani, 2006a,b). Therefore, our conclusions did not depend, from a logical point of view, on whether or not other genes in addition to Trpm5 have influenced the results.

It is important to note that, in addition to taste cells, the TRPM5 channel is also expressed in the gastrointestinal tract (Bezençon et al., 2007). Although it has been shown that the presence of the TRPM5 channel in the gut is not required for the ability of carbohydrates to exert their postingestive reinforcing effects (de Araujo et al., 2008), it could be argued that the tasteindependent preferences for glucose derive from an inability of Trpm 5 knock-out mice to appropriately absorb and/or metabolize amino acids. We provided four lines of evidence against this possibility. First, we have shown that wild-type mice will produce increased number of licks to water paired with glucose intragastric infusions compared with licks paired to serine infusions (see Results) (supplemental Fig. S2, available at www.jneurosci.org as supplemental material). Indeed, if the differential levels of glucose and serine intake observed in $\mathrm{KO}$ mice were attributable to these animals lacking TRPM5 expression in the gut, then wildtype animals implanted with gastric catheters should have produced approximately the same number of licks to water when being infused with either glucose or serine. Second, this result was confirmed in analogous experiments in which gut delivery of nutrients were bypassed by intravenous infusions, so that wildtype mice will produce increased number of licks to water when paired to glucose intravenous infusions compared with licks paired to serine intravenous infusions. Third, we have also shown that Trpm5 KO mice retain the ability to detect the differential metabolic effects produced by two different amino acids (serine vs arginine) even if unable to discriminate between their tastes (supplemental Fig. S2, available at www.jneurosci.org as supplemental material). Fourth, there were no differences in blood urea nitrogen levels between the two genotypes, ruling out major abnormalities in protein absorption and/or amino acid metabolism in knock-out animals. Future studies must determine the exact role of gut-expressed TRPM5 channels in diet selection.

Although there is no evidence, to our knowledge, to suggest that mutations associated with taste receptor genes are associated with metabolic dysfunctions, we believe that our data can be useful to further our understanding on the role of sweetness perception in sugar overconsumption. Because soft drinks constitute a major source of sugar energy (Bray et al., 2004), one would expect that introducing artificially sweetened beverages to the market would curb overall caloric intake. However, the availability of noncaloric artificially sweetened drinks did not limit overall sugar intake (Saris, 2003), suggesting the existence of sweetness- independent signals that function as reinforcers of carbohydrate consumption. Our data suggest that glucose utilization, independently of sweetness perception per se, plays a major role in determining preferences for sugar-based beverages and foods. This effect would at least in part result from a direct modulation of striatal dopamine circuits by glucose oxidation. Reward signals generated from fuel utilization must therefore be taken into account whenever low-calorie, restrictive diets are to be prescribed. In fact, lacking appropriate glucose oxidation in a number of tissues might result in alteration of brain reward systems and consequently in lack of compliance, a major challenge often associated with long-term weight management (Hainer et al., 2008).

Previous behavioral studies compared the postingestive effects produced by proteins versus carbohydrates using flavornutrient conditioning paradigms. In particular, Pérez et al. (1996) have found, in contrast to our results, no differences in preference patterns between flavors associated with intragastric infusions of either carbohydrate or proteins. However, the Pérez et al. (1996) study differs from ours on at least two important aspects. First, Pérez et al. (1996) used separate experiments to condition flavors to intragastric infusions of either carbohydrate or proteins; therefore, the nutrients postingestive effects were compared not against each other but against those produced by noncaloric control solutions. This aspect of the design (in which animals are attracted to conditioned flavors according primarily to their caloric value) might have contributed to the observed isopreferences. Furthermore, these investigators made use of intragastric infusions of complex carbohydrates and proteins (polycose vs casein, respectively), raising the possibility that digestive processes independent from postabsorptive metabolic processes influenced the behavioral choices. More recently, an interesting series of studies by Kondoh, Torii, and colleagues have demonstrated specific postingestive effects produced by L-glutamate versus glucose in flavor nutrient-conditioning paradigms (Kondoh and Torii, 2008). In addition to sugar versus L-amino acid conditioning having occurred during different sessions, this latest study differs from ours with respect to the glucose concentrations used: Kondoh et al. (2008) intentionally used molar glucose concentrations that are insufficient to induce conditioning ( $\sim 60 \mathrm{~mm}$ ). Future studies must directly compare the postingestive effects produced by complex carbohydrates and proteins.

Our indirect calorimetry data implicating glucose oxidation as a regulator of sugar intake is directly related to the concept proposed by Friedman, Tordoff, and colleagues that food intake patterns are ultimately controlled by signals generated during the oxidation of metabolic fuels (Friedman, 1989, 1991). However, by assuming that a reinforcing stimulus is generated during intramitochondrial oxidative phosphorylation (Friedman, 1991), the theory implies that such stimulus is independent of the type of fuel being oxidized. Our results suggest instead that it is the ability of a particular nutrient to specifically induce glucose oxidation, rather than its caloric value per se, that constitutes the relevant signal leading to increased sugar intake [on the reciprocal effects of sweet taste on energy expenditure, see Swithers and Davidson (2008)]. Futures studies must address the issue of whether selective blockage of glucose oxidation (Friedman and Tordoff, 1986), compared with other fuels, specifically impairs glucose intake in Trpm 5 knock-out mice.

One principal finding of our study concerns the ability of dopamine brain systems to detect nutrient-specific physiological changes independently of taste input or caloric load. We showed that differential changes in extracellular levels of dopamine in accumbens could be induced via intragastric infusions of glucose 
versus isocaloric serine. It has been established that dopamine release in this brain region reflects the hedonic value of sugars in the absence of either calorie absorption (Hajnal et al., 2004) or taste input (de Araujo et al., 2008). Here we provided evidence in favor of the more general hypothesis that specific nutrients, even at isocaloric concentrations, can differentially affect brain neurotransmitter systems. Nutrient-specific changes in dopamine levels were also detected in the dorsal striatum, although the characteristics and temporal course of the response differed from those observed in the nucleus accumbens of the ventral striatum. In any case, this finding is consistent with previous studies implicating the dorsal aspect of the striatum in feeding behaviors in both animals (Sotak et al., 2005) and humans (Small et al., 2003). One novel aspect of our findings concerns the fact that such responses in dorsal striatum can be, likewise in the nucleus accumbens, induced by direct stimulation of the gastrointestinal tract. It remains, however, to be determined the exact pathways allowing nutrient-specific action on brain dopamine cells. Because midbrain dopamine neurons strongly express receptors for metabolic hormones including insulin and leptin (Figlewicz, 2003; Palmiter, 2007), one attractive hypothesis concerns the possibility that different nutrients can exert their opposing effects on brain dopamine circuits as a function of their ability to stimulate differential secretion of insulin and/or leptin (Fulton et al., 2006; Hommel et al., 2006). However, our results showing that infusions of the glucose metabolism inhibitor 2-DG strongly suppressed dopamine release in striatum indicate instead that glucose utilization, rather hormonal signaling, is the principal stimulus regulating striatal dopamine release during glucose ingestion. This effect was reversed by intravenous glucose infusions that contributed to restore glucose oxidation rates, and sweetinsensitive knock-out mice did in fact attribute higher reward value to glucose solutions after 2-DG injections. 2-DG injections have long been known to significantly increase food intake after both systemic and intraventricular infusions (Benoit and Davidson, 1996; Singer and Ritter, 1996). In addition, substantia nigra perfusion with 2-DG increases GABAergic signaling in this region, possibly influencing dopamine release in striatum (During et al., 1995). In any case, our study contributes to these findings by indicating that dopamine circuits might function as a main regulator of the appetite-inducing effects of 2-DG, an effect that did not depend on the presence of taste signaling.

Although the notion that dopamine signaling is closely linked to food intake remains unchallenged, the precise role played by dopamine in feeding behavior remains unresolved. The early emphasis on hedonia and primary reward (Wise, 2006) has shifted toward alternative, more elaborate hypotheses (Wise, 2006; Salamone et al., 2009). Of particular interest is the possibility that dopamine regulates effort-based processes during behavioral activation (Salamone et al., 2007, 2009). Dopamine signaling has also been linked to reward prediction (Schultz, 1998) and incentive salience attribution (Berridge, 2007). In any event, we note that our data are in principle consistent with the different interpretations of dopamine function and solely indicate that glucose metabolism is a potential regulator of all these alternative mechanisms.

A note must be made at this point regarding the possibility that metabolic signals other than glucose utilization might have influenced the behavioral and neurochemical effects observed in this study. In fact, it is plausible to conceive that both hormonal and fuel utilization signals can act in concert to regulate brain neurotransmitter systems. In this regard, we envisage a particularly central role for the metabolism-controlling gut factor ghre- lin (Tschöp et al., 2000) in modulating dopamine levels during situations associated with low blood glucose levels, including starvation. In fact, a recent study by Andrews et al. (2009) has demonstrated that ghrelin promotes tyrosine hydroxylase gene expression in substantia nigra concomitantly to increasing dopamine concentration in striatum. In addition, Andrews et al. (2009) have also shown that peripheral ghrelin contributes to the maintenance and protection of normal nigrostriatal dopamine function via UCP2-dependent mitochondrial mechanisms. More generally, the body of data produced by Horvath, Andrews, and colleagues (Andrews et al., 2008, 2009; Horvath et al., 2009) indicates that, under conditions of excessively low blood glucose levels, increased ghrelin signaling may activate mitochondrial respiration and promote fatty acid oxidation in dopamine neurons as an alternative fuel source. Such actions of ghrelin might be critical for the maintenance, in hypoglycemic animals, of lifepreserving behavioral actions such as foraging. The role of ghrelin in regulating dopamine function during periods of low glucose delivery to the brain is an important topic for future research.

Finally, it is noticeable that genetically engineered dopaminedeficient mice retain the ability to prefer sucrose over water (Cannon and Palmiter, 2003). Such ability may be mediated by taste relays of the brainstem that in principle are not under the direct control of dopamine neurons. However, the same group has also demonstrated that dopamine-deficient mice are unable to sustain appropriate levels of feeding and in particular that dysregulation of dopamine signaling in the dorsal striatum is sufficient to induce hypophagia (Sotak et al., 2005). Therefore, although taste-based preferences seemed to be preserved in the absence of dopamine tone, normal feeding behaviors did not. Because we described in this study significant increases in dopamine levels during sugar absorption that do not depend on sweetness perception, we believe our data actually contribute to strengthen the concept that dopamine acts to regulate feeding primarily via metabolic, rather than gustatory, pathways. In other words, our data are consistent with both normal gustatory preferences (Cannon and Palmiter, 2003) and abnormal, hypophagic behaviors (Sotak et al., 2005; Palmiter, 2007) in dopaminedeficient mice.

In summary, our results show that sugar-specific behavioral preferences and dopamine release will develop independently of sweetness or caloric value while being regulated by glucose oxidation levels. Future research must determine the mechanisms through which the metabolic utilization of nutrients regulates neurotransmitter release.

\section{References}

Andrews ZB, Liu ZW, Wallingford N, Erion DM, Borok E, Friedman JM, Tschöp MH, Shanabrough M, Cline G, Shulman GI, Coppola A, Gao XB, Horvath TL, Diano S (2008) UCP2 mediates ghrelin's action on NPY/ AgRP neurons by lowering free radicals. Nature 454:846-851.

Andrews ZB, Erion D, Beiler R, Liu ZW, Abizaid A, Zigman J, Elsworth JD, Savitt JM, DiMarchi R, Tschoep M, Roth RH, Gao XB, Horvath TL (2009) Ghrelin promotes and protects nigrostriatal dopamine function via a UCP2-dependent mitochondrial mechanism. J Neurosci 29:14057-14065.

Atwater WO (1910) Principles of nutrition and nutritive values of food. In: U.S. Farmer's Bulletin. Washington, DC: United States Department of Agriculture.

Bachmanov AA, Beauchamp GK (2008) Amino acid and carbohydrate preferences in C57BL/6ByJ and 129P3/J mice. Physiol Behav 93:37-43.

Benoit SC, Davidson TL (1996) Interoceptive sensory signals produced by 24-hr food deprivation, pharmacological glucoprivation, and lipoprivation. Behav Neurosci 110:168-180.

Berridge KC (2007) The debate over dopamine's role in reward: the case for incentive salience. Psychopharmacology 191:391-431. 
Bezençon C, le Coutre J, Damak S (2007) Taste-signaling proteins are coexpressed in solitary intestinal epithelial cells. Chem Senses 32:41-49.

Bray GA, Nielsen SJ, Popkin BM (2004) Consumption of high-fructose corn syrup in beverages may play a role in the epidemic of obesity. Am J Clin Nutr 79:537-543.

Buch S, Melcher C, Bauer M, Katzenberger J, Pankratz MJ (2008) Opposing effects of dietary protein and sugar regulate a transcriptional target of Drosophila insulin-like peptide signaling. Cell Metab 7:321-332.

Cannon CM, Palmiter RD (2003) Reward without dopamine. J Neurosci 23:10827-10831.

Damak S, Rong M, Yasumatsu K, Kokrashvili Z, Pérez CA, Shigemura N, Yoshida R, Mosinger B Jr, Glendinning JI, Ninomiya Y, Margolskee RF (2006) Trpm5 null mice respond to bitter, sweet, and umami compounds. Chem Senses 31:253-264.

de Araujo IE, Oliveira-Maia AJ, Sotnikova TD, Gainetdinov RR, Caron MG, Nicolelis MA, Simon SA (2008) Food reward in the absence of taste receptor signaling. Neuron 57:930-941.

Dotson CD, Spector AC (2004) The relative affective potency of glycine, L-serine and sucrose as assessed by a brief-access taste test in inbred strains of mice. Chem Senses 29:489-498.

During MJ, Leone P, Davis KE, Kerr D, Sherwin RS (1995) Glucose modulates rat substantia nigra GABA release in vivo via ATP-sensitive potassium channels. J Clin Invest 95:2403-2408.

Ferrer JC, Favre C, Gomis RR, Fernández-Novell JM, García-Rocha M, de la Iglesia N, Cid E, Guinovart JJ (2003) Control of glycogen deposition. FEBS Lett 546:127-132.

Figlewicz DP (2003) Adiposity signals and food reward: expanding the CNS roles of insulin and leptin. Am J Physiol Regul Integr Comp Physiol 284:R882-R892.

Friedman MI (1989) Metabolic control of food intake. Bol Asoc Med P R $81: 111-113$

Friedman MI (1991) Metabolic control of caloric intake. In: Chemical senses (Friedman MI, Tordoff MG, Kare MR, eds). New York: Dekker.

Friedman MI, Tordoff MG (1986) Fatty acid oxidation and glucose utilization interact to control food intake in rats. Am J Physiol 251:R840-R845.

Fulton S, Pissios P, Manchon RP, Stiles L, Frank L, Pothos EN, Maratos-Flier E, Flier JS (2006) Leptin regulation of the mesoaccumbens dopamine pathway. Neuron 51:811-822.

Glendinning JI, Jerud A, Reinherz AT (2007) The hungry caterpillar: an analysis of how carbohydrates stimulate feeding in Manduca sexta. J Exp Biol 210:3054-3067.

Grigson PS, Hajnal A (2007) Once is too much: conditioned changes in accumbens dopamine following a single saccharin-morphine pairing. Behav Neurosci 121:1234-1242.

Hainer V, Toplak H, Mitrakou A (2008) Treatment modalities of obesity: what fits whom? Diabetes Care 31:S269-S277.

Hajnal A, Smith GP, Norgren R (2004) Oral sucrose stimulation increases accumbens dopamine in the rat. Am J Physiol Regul Integr Comp Physiol 286:R31-R37.

Hernandez L, Hoebel BG (1988) Food reward and cocaine increase extracellular dopamine in the nucleus accumbens as measured by microdialysis. Life Sci 42:1705-1712.

Hommel JD, Trinko R, Sears RM, Georgescu D, Liu ZW, Gao XB, Thurmon JJ, Marinelli M, DiLeone RJ (2006) Leptin receptor signaling in midbrain dopamine neurons regulates feeding. Neuron 51:801-810.

Horvath TL, Andrews ZB, Diano S (2009) Fuel utilization by hypothalamic neurons: roles for ROS. Trends Endocrinol Metab 20:78-87.

Jéquier E, Acheson K, Schutz Y (1987) Assessment of energy expenditure and fuel utilization in man. Annu Rev Nutr 7:187-208.

Ji H, Bachmanov AA (2007) Differences in postingestive metabolism of glutamate and glycine between C57BL/6ByJ and 129P3/J mice. Physiol Genomics 31:475-482.
Kondoh T, Torii K (2008) Brain activation by umami substances via gustatory and visceral signaling pathways, and physiological significance. Biol Pharm Bull 31:1827-1832.

Lewis SR, Ahmed S, Khaimova E, Israel Y, Singh A, Kandov Y, Kest B, Bodnar RJ (2006) Genetic variance contributes to ingestive processes: a survey of 2-deoxy-d-glucose-induced feeding in eleven inbred mouse strains. Physiol Behav 87:595-601.

Markison S, Gietzen DW, Spector AC (1999) Essential amino acid deficiency enhances long-term intake but not short-term licking of the required nutrient. J Nutr 129:1604-1612.

Merrill AL, Watt BK (1973) Energy value of foods: basis and derivation, Vol 74. Washington, DC: United States Department of Agriculture, Agricultural Research Service.

Palmiter RD (2007) Is dopamine a physiologically relevant mediator of feeding behavior? Trends Neurosci 30:375-381.

Pérez CA, Huang L, Rong M, Kozak JA, Preuss AK, Zhang H, Max M, Margolskee RF (2002) A transient receptor potential channel expressed in taste receptor cells. Nat Neurosci 5:1169-1176.

Pérez C, Ackroff K, Sclafani A (1996) Carbohydrate- and proteinconditioned flavor preferences: effects of nutrient preloads. Physiol Behav 59:467-474.

Roper SD (2007) Signal transduction and information processing in mammalian taste buds. Pflugers Arch 454:759-776.

Salamone JD, Correa M, Farrar A, Mingote SM (2007) Effort-related functions of nucleus accumbens dopamine and associated forebrain circuits. Psychopharmacology 191:461-482.

Salamone JD, Correa M, Farrar AM, Nunes EJ, Pardo M (2009) Dopamine, behavioral economics, and effort. Front Behav Neurosci 3:13.

Saris WH (2003) Sugars, energy metabolism, and body weight control. Am J Clin Nutr 78:850S-857S.

Schultz W (1998) Predictive reward signal of dopamine neurons. J Neurophysiol 80:1-27.

Sclafani A (2001) Post-ingestive positive controls of ingestive behavior. Appetite $36: 79-83$

Sclafani A (2006a) Enhanced sucrose and Polycose preference in sweet "sensitive" (C57BL/6J) and "subsensitive" (129P3/J) mice after experience with these saccharides. Physiol Behav 87:745-756.

Sclafani A (2006b) Sucrose motivation in sweet "sensitive" (C57BL/6J) and "subsensitive" (129P3/J) mice measured by progressive ratio licking. Physiol Behav 87:734-744.

Singer LK, Ritter S (1996) Intraventricular glucose blocks feeding induced by 2-deoxy-D-glucose but not mercaptoacetate. Physiol Behav 59:921923.

Small DM, Jones-Gotman M, Dagher A (2003) Feeding-induced dopamine release in dorsal striatum correlates with meal pleasantness ratings in healthy human volunteers. Neuroimage 19:1709-1715.

Sotak BN, Hnasko TS, Robinson S, Kremer EJ, Palmiter RD (2005) Dysregulation of dopamine signaling in the dorsal striatum inhibits feeding. Brain Res 1061:88-96.

Swithers SE, Davidson TL (2008) A role for sweet taste: calorie predictive relations in energy regulation by rats. Behav Neurosci 122:161-173.

Tschöp M, Smiley DL, Heiman ML (2000) Ghrelin induces adiposity in rodents. Nature 407:908-913.

Wise RA (2006) Role of brain dopamine in food reward and reinforcement. Philos Trans R Soc Lond B Biol Sci 361:1149-1158.

Young A (2005) Inhibition of glucagon secretion. Adv Pharmacol 52: 151-171.

Zhang Y, Hoon MA, Chandrashekar J, Mueller KL, Cook B, Wu D, Zuker CS, Ryba NJ (2003) Coding of sweet, bitter, and umami tastes: different receptor cells sharing similar signaling pathways. Cell 112:293-301. 